\title{
Using maximum Vertical Integrated Liquid (VIL) maps for identifying hail-affected areas: an operative application for agricultural purposes
}

\author{
T. Rigo ${ }^{1}$ and C. Farnell ${ }^{1}$ \\ ${ }^{1}$ Meteorological Service of Catalonia \\ Received: 17-V-2019 - Accepted: 30-X-2019 - Original version
}

Correspondence to: tomeu.rigo@gencat.cat

\begin{abstract}
Catalonia (NE of the Iberian Peninsula) is commonly affected by severe and non-severe hail events. Every year, hailstorms cause considerable damage to agriculture areas. Therefore, the Meteorological Service of Catalonia (SMC) started a collaborative project with the Department of Agricultural, Livestock and Fishing (DARP) of the Generalitat de Catalunya in 2016. This project has the goal of providing geo-referenced fields of the maximum daily value of the Vertical Integrated Liquid (VIL) for an area of interest. The resulting map allows the DARP technicians of the particular region to focus their fieldwork analysis over the pixels where the VIL values exceed a certain threshold. This work is part of the SMC's global project of nowcasting and hail diagnosis. This paper shows the procedure and some examples of the tool application, adapted to the necessities of the DARP technicians over the years. The algorithm has been found to be a good pointer of those hail-affected regions, mainly in combination with an agriculture exploitation boundary layer.
\end{abstract}

Key words: Hail, size estimation, radar, agriculture, hailpad

\section{Introduction}

Hail events occur in Catalonia (NE of the Iberian Peninsula) several times a year. The climatic analysis presented by Punge et al. (2017) and Punge et al. (2014) shows how the area of study exhibits the highest frequency of hail events in Europe, with similar values to the Southern Alps (Fig. 1). This analysis was made by considering satellite imagery, searching for overshooting patterns which closely correlate with large hail. In any case, the global estimation made using thermodynamic parameters obtained from numerical models (Allen, 2017) shows how the frequency of severe hail events in Catalonia is far from the absolute maximum values (Argentinian Plains, Central Plains of the United States, Central Atlantic Coast of Africa and $\mathrm{N}$ and $\mathrm{NE}$ of India). It is worth noting that there is no global hail climatology made using weather radar, either worldwide or just for Europe. In any case, the previous methodologies have been compared locally with ground observations or radar fields, showing a good correlation.
Due to agricultural interest, the Lleida Plain has a long tradition in the study of hailstorms. Thus, the hail events that have occurred in the area of interest have been widely analysed in many pieces of research, from the climatic point of view to the specific study of more interesting episodes (Aran et al., 2007; Farnell and Llasat, 2013; García-Ortega et al., 2012; Ceperuelo et al.; Ramis et al., 1997; Aran et al., 2011). One of the central data sources is a very dense hailpad network, which provides information concerning hailstone dimensions, the number of impacts and other variables (Palencia et al., 2007). These data give interesting climatic trends on the number of events, size distribution and additional results. In addition, it is possible to model each hail case because of the high spatial resolution. However, the issue of the network is that it is not helpful for realtime surveillance tasks or the diagnosis of the effects of the hailstorms.

There are some references in literature concerning the use of Vertical Integrated Liquid (VIL, Boudevillain and Andrieu (2003)) as an estimator of hail and severe hail. 


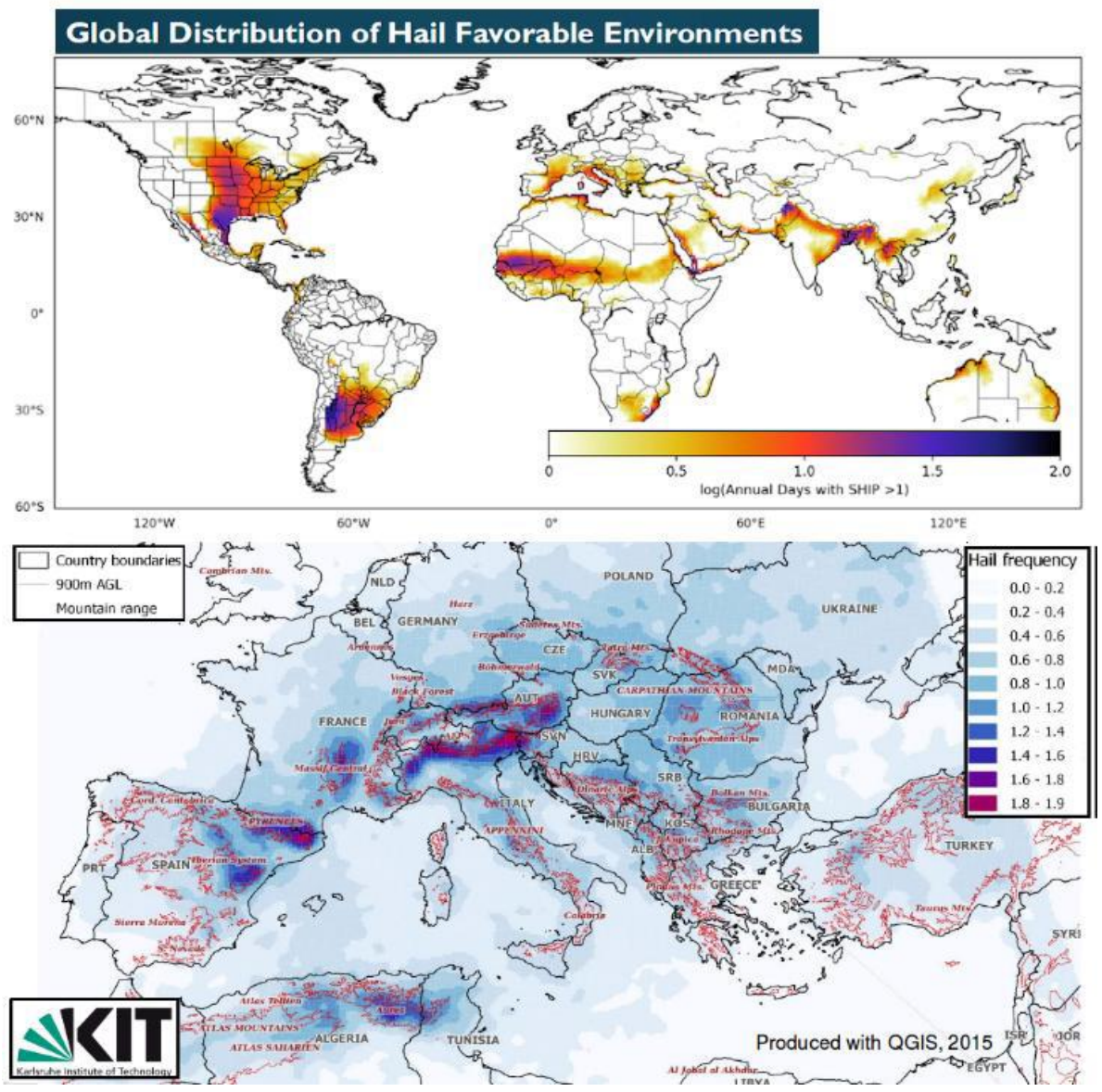

Figure 1: Different ways of estimating the yearly hail frequency. Top: World distribution provided by Allen (2017), considering thermodynamic parameters. Bottom: The same for Europe, but using the overshooting from the Meteosat Second Generation imagery (Punge et al. (2017), see the text for more information).

For instance, Amburn and Wolf (1997) show that there is a high correlation between VIL and hail, but the values of the product are highly dependent on the type of air masses. Additionally, Hirano and Maki (2010) found a high influence on the product values depending on the way of calculating the product using an X-band radar. Further progress was made by Edwards and Thompson (1998), who found that VIL also has a high correlation with the geographic conditions and not only for the annual period.

VIL was one of the methodologies for the diagnosis of hail in thunderstorms developed in the Meteorological Service of Catalonia in early 2000. The first part of the VIL technique was the generation of a 6-minute composition for the entire area of Catalonia. The composition is generated considering the maximum value method. The VIL product is calculated in those areas with volumetric radar data, combining the height and the reflectance of each pixel in a column, which is vertically integrated. VIL can be used for instantaneous imagery or, on the other hand, by considering the daily maximum value. In this analysis, the latter has been used, in a similar way as in previously mentioned works. The second one (Probability of Hail or $\mathrm{POH}$ ) was similar to the Waldvogel technique (Waldvogel et al., 1979), considering the height differences between the echo-top products (Delobbe and Holleman, 2006) and the iso-zero level estimated by a Numerical Weather Prediction (NWP) for generating Probability of Hail (POH) fields. In the second case, the equation was calibrated using the data from the hailpad network managed by the Vegetative Defence Association (ADV) of the Terres de Ponent, in collaboration with the University of Leon (ULe) and the SMC. A study revealed the excellent performance of the second technique for determining hail (Porras et al.). They were the only methodologies considered in the surveillance tasks on hailstorms.

Since 2014, the SMC has expanded its efforts into the knowledge of hail-bearing thunderstorms. In this sense, the algorithm of identification, characterization, tracking and nowcasting of convective cells has been adapted to the hail surveillance tasks (Rigo and Llasat, 2016; del Moral et al., 2018). Another improvement in the hail analysis program consisted of the generation of preliminary fields for estimating the size of the precipitated hail. These maps were made considering different radar products and the observations on site (Farnell et al., 2018a). The cokriging technique merged the two sources into one field, with VIL being the product that generally fits better with the ground data, ahead of other products such as surface reflectance 


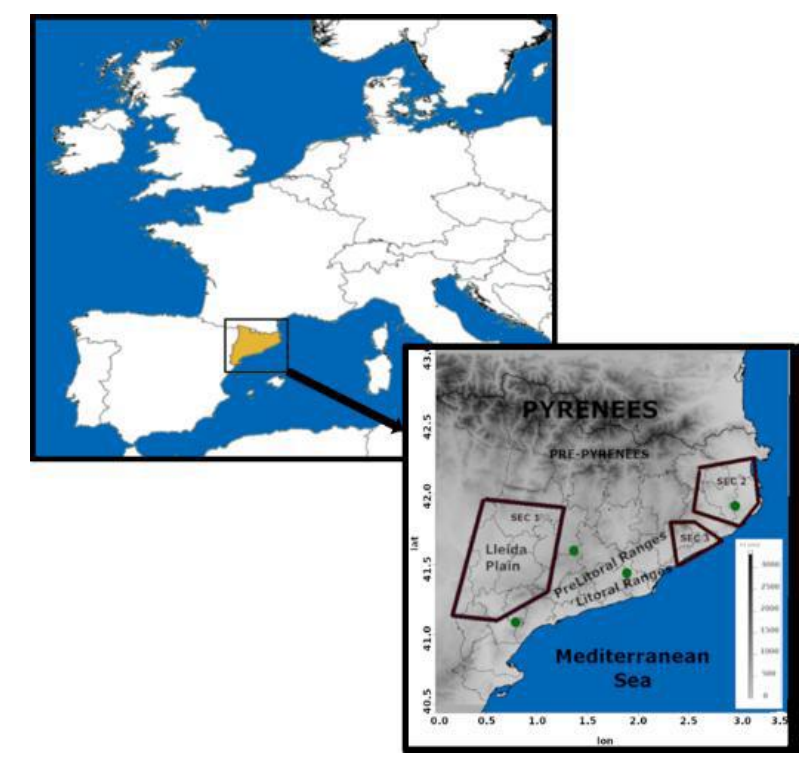

Figure 2: Top: General map of Europe, with the rectangle indicating Catalonia. Bottom: Main orographic characteristics of the area of interest. The purple lines mark the three different sections ( $\sec 1$, sec 2 and sec 3) with collaboration of the SMC and DARP. Green dots indicate the XRAD radar location.

or TOP45. In cases of small hail, the differences are relatively low, with a relative error of around $0.5 \mathrm{~cm}$ between the estimation and the true ground measurements for both products. However, when large hail occurs, the differences in the estimation are more substantial $(1.3 \mathrm{~cm}$ for VIL and 1.7 for TOP45). It is also possible to get a real map of the effects with one ground measure every $10 \mathrm{~km}^{2}$. The last point of the SMC project about hail surveillance consists of the nowcasting of severe weather phenomena occurrence: the lightning jump algorithm (Farnell et al., 2017, 2018b). This tool is based on experimental techniques developed in the USA (Schultz et al., 2011) but with a different configuration, in order to adapt to the operational chain of the SMC in 2017. The algorithm distinguishes sudden increments in the total lightning activity (flash rate per minute) in a thunderstorm, which relates to large updrafts that cause electrical charge separations.

In all the previous projects, the SMC staff detected the necessity to get more information in real time from the society. With this in mind, the SMC developed the citizen campaign called "Pick Up the Hailstone/Plega la Pedra"), which has the objective of collecting hail measurements using geo- and time-referenced photographs. Every observation must incorporate a reference object (a coin or a ruler, preferentially) that gives an idea of the approximate size of the maximum hail. The data provided by this campaign have helped to tune the tools developed in the projects mentioned.

In the context of the ADV collaboration, the SMC technicians observed that the $\mathrm{POH}$ products correctly diagnosed the hail occurrence in most of the thunderstorms. In contrast, $\mathrm{POH}$ did not allocate hail on the ground precisely, or, what is the same, the areas with the highest $\mathrm{POH}$ values did not match the biggest hail measurements on the terrain. This result coincides with the one obtained in the analysis made by Farnell et al. (2018a) and it is the consequence of the Waldvogel technique configuration: the maximum $\mathrm{POH}$ occurs at the time of maximum cloud development, which generally does not coincide with the time of hail occurrence on the ground. Bearing in mind the thunderstorm speed, the ratio of this velocity and the difference between both times (maximum $\mathrm{POH}$ and hailfall) gives the distance between the diagnosis and the observation.

Finally, the SMC has collaborated with the Department of Agriculture, Livestock and Fishing (DARP) of the Generalitat de Catalunya since 2012, in order to determine the areas with more probability of being hit by hail. The preliminary step consisted of requesting some georeferenced maps for particular events in the Lleida Plain area. The collaboration has increased in recent years and nowadays consists of the generation of these maps for three of the four Catalan provinces (Lleida, Girona and Barcelona). The charts give the maximum daily VIL estimation for all the points of the required grid. The DARP staff request this product each time that an event affects vast areas of agricultural exploitation. Then, the DARP fieldwork over the terrain considers the SMC map, allowing the generation of an accurate report about the hail event, with the damage estimation for each plot. This report is returned to the SMC, helping to tune the diagnosis or nowcasting tools.

This paper shows some details about the procedure and the product generation, as well as some examples of its application. In the first section, we present the domain of interest and some climatic characteristics of hail in Catalonia. Next, the document introduces the operational methodology and some technical aspects of the product. The third section consists of the presentation of some cases of interest, which lead to some discussions of future improvements of the method. Finally, we provide some conclusions about the procedure.

\section{Area of interest and climatology of hail}

Catalonia is a region in the NE of the Iberian Peninsula with a very complex topography. The main orographic features are (Fig. 2): the Pyrenees and the Pre-Pyrenees are two ranges that run from West to East, with heights of over 3,000 and 2,000 $\mathrm{m}$ ASL, respectively. In addition, the Littoral and Pre-Littoral ridges move along the area, from SW to NE, the first one reaching maximum altitudes of 1,800 $\mathrm{m}$ ASL, while the second has a maximum of $900 \mathrm{~m}$ ASL, but with very steep slopes. Between these mountain systems, there are different plains and depressions, with the Lleida Plain being the largest and most important one. The final geographic element to bear in mind is the Mediterranean Sea, which provides warm, moist air to the region, mainly during summer and autumn. The combination of all these elements and the cold air from the $\mathrm{N}$ or the $\mathrm{E}$, produces very severe thunderstorms in the region (Farnell et al., 2018b). 


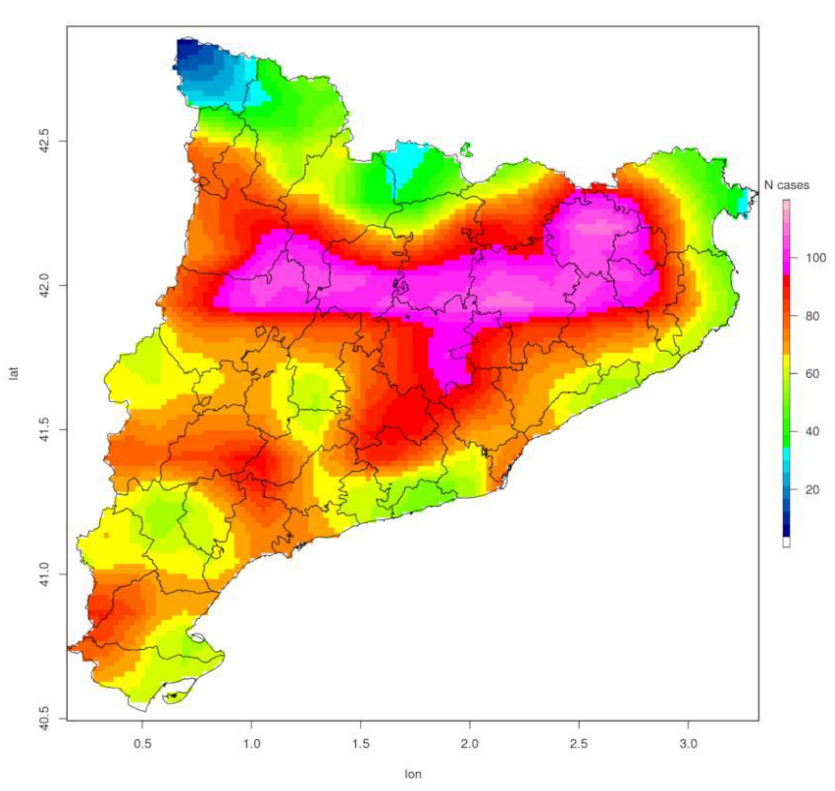

Figure 3: Normalized map of the hail frequency in Catalonia for the period between 2006 and 2015, considering radar data and the existing ground registers (see the text for more about the limitations of this source).

As mentioned before, during the early 2010 s, the number of hail events identified in Catalonia was very poor. Just the hailpad network and the ADV staff in the Lleida Plain provided most of the registers included in the SMC's severe weather database (Farnell et al., 2017). Except for some exceptional cases that occurred in other sectors, which were found using newspapers, among other sources. Moreover, not all the regions of the Catalan territory are well covered in all events, as occurs in other areas around the world (Schuster et al., 2005; Saltikoff et al., 2010). This fact is more evident during night hailfall or cases that occur in lowdensity populated regions. In any case, the radar-derived maps show a clear maximum of activity in the Central part of the Pre-Pyrenees (see, for instance, the density distribution of thunderstorms presented by del Moral et al. (2017). Moreover, the combination of the radar VIL product and the ground registers for the period (see Fig. 3) confirms the previous perception, bearing in mind that the lack of ground registers can notably change the configuration, reinforcing some of the maxima even more.

In order to minimize the lack of ground information, the SMC developed the citizen science campaign "Pick Up the Hailstone". This interactive project has allowed the verification of the radar maxima area and has, in addition, shown that currently it is hard to create a precise climatology of hail events in Catalonia. Fig. 4 shows the map of all hail registers (whether severe or not) reported during the field campaign (2017 and 2018), confirming that the areas of maxima activity almost coincide with those of Fig. 3. On the other hand, the probability of occurrence of a hail event in any part of the Catalan territory is not null. Farnell et al. (2018a) showed that the combination of radar data with

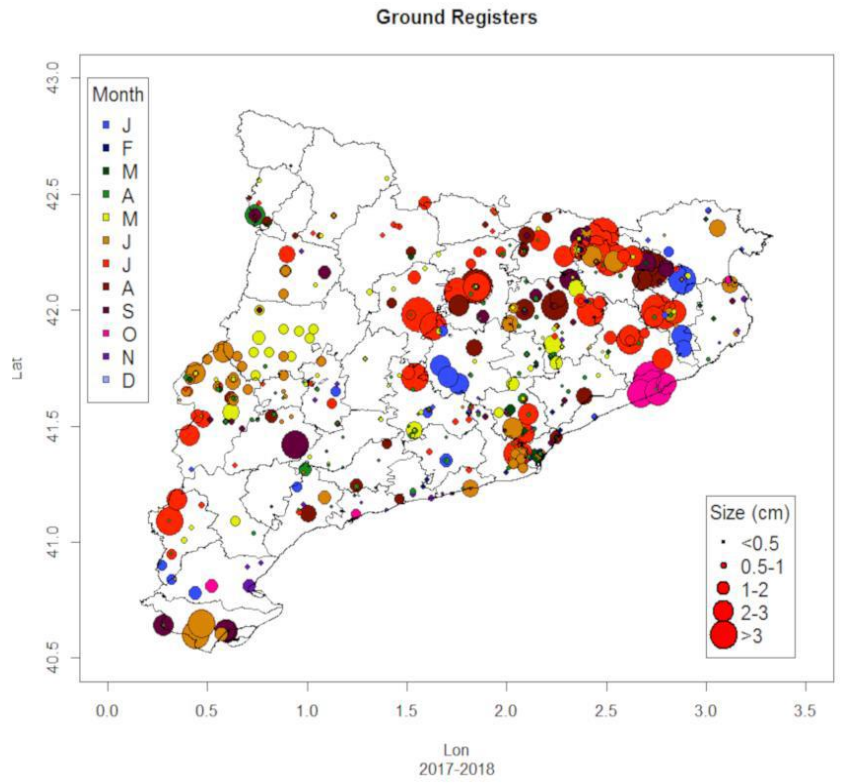

Figure 4: Map of the hail registers in Catalonia from the 2017 and 2018 citizen campaign "Pick Up the Hailstone".

ground observations in a spatial resolution of $10 \times 10 \mathrm{~km}^{2}$ helps to get a representative field of the hail size. In any case, the information provided by different sources plays a significant role in the quantification of the episodes (see, for instance, Ortega et al. (2016)).

Regarding the monthly distribution, Table 1 shows how the maxima period for both, non-severe (hail under $2 \mathrm{~cm}$ in diameter) and severe cases (hail equal or more than 2 $\mathrm{cm}$ in size) is between July and August, followed by the April to June period. However, as it occurs with the spatial distribution, the probability of occurrence of a hail event is not null for the whole year.

Therefore, we can conclude that the hail effects in Catalonia are marked by a large variability in time and space, as well as by a high probability of occurrence of hail in practically all the territory, with two marked maxima: the Western region (Lleida Plain) and the Central part (PrePyrenees range). In this context, and aware of the importance of agriculture for the Catalan economy, understanding the mechanisms in each event is necessary to improve the tasks of mitigating hailstorms. In this context, the collaboration between the SMC and the DARP came into being.

\section{Data and Methodology}

We have used two types of data sources in this analysis. The first one is the maximum daily VIL field generated when DARP staff requested it because of knowledge of a hail event in their section (see Fig. 2). This field has a spatial resolution of $1 \times 1 \mathrm{~km}^{2}$ and covers the region and its neighbouring area. The VIL product is generated every 6 minutes in a composite of the four radars of the SMC network (XRAD), 
Table 1: Monthly distribution of the non-severe and severe events estimated using the combination of weather radar and ground register (period 2006-2015).

\begin{tabular}{ccc}
\hline MONTH & NON-SEVERE & SEVERE \\
\hline Jan & 2 & 2 \\
Feb & 7 & 2 \\
Mar & 16 & 3 \\
Apr & 61 & 5 \\
May & 53 & 4 \\
Jun & 46 & 12 \\
Jul & 72 & 28 \\
Aug & 76 & 13 \\
Sep & 49 & 16 \\
Oct & 27 & 6 \\
Nov & 20 & 2 \\
Dec & 3 & 0
\end{tabular}

covering all Catalonia and the surrounding regions. The algorithm computes the maximum daily VIL at each pixel of the selected surface. This type of map provides an estimation of the probability of hail at that surface. However, there is not an exact relationship between the value and the hail size (Edwards and Thompson, 1998). The ground information consisted of two sources. The first one is the percentage of damage in each municipality of the section considered. The last source includes all the photos that allow the maximum hail size recorded in each place to be determined.

The methodology used in the project has been modified over the years, adapting it to the changing necessities of the DARP technicians. These changes are the result of better knowledge of the products and their capabilities. The first work started in 2012 when the maps were generated using daily quantitative precipitation estimation (QPE) obtained from the XRAD. In this context, the DARP staff had to focus on those regions with very substantial overestimation of the rainfall values (Fig. 5). As the figure shows, the QPE product does not discriminate between types of rainfall. Because of this, and bearing in mind the experience of the SMC technicians, it was decided to consider 50 $\mathrm{mm}$ as the threshold for discriminating as probable hail precipitation. However, this value is very dependent on the event and, in most cases, the technicians need to modify it manually. In order to demonstrate this limitation, the SMC team generated off-line the maximum daily VIL map for the same case shown in the example. In this case, it is easy to observe how, in some areas, the imposed threshold produced an overestimation of the hail probability, while, in others, the estimation was under the values shown by the VIL. Furthermore, the QPE was not able to reproduce the high spatial variability of the hailfall. It is worth noting that the $\mathrm{POH}$ fields also provided better estimations of the hail occurrence than QPE (not shown), and they were used temporarily as a solution.

A new phase started in 2015, when the DARP staff decided to take a step forward and make more regular the use of the product. From the preliminary conversations between the technicians of the SMC and of the DARP,

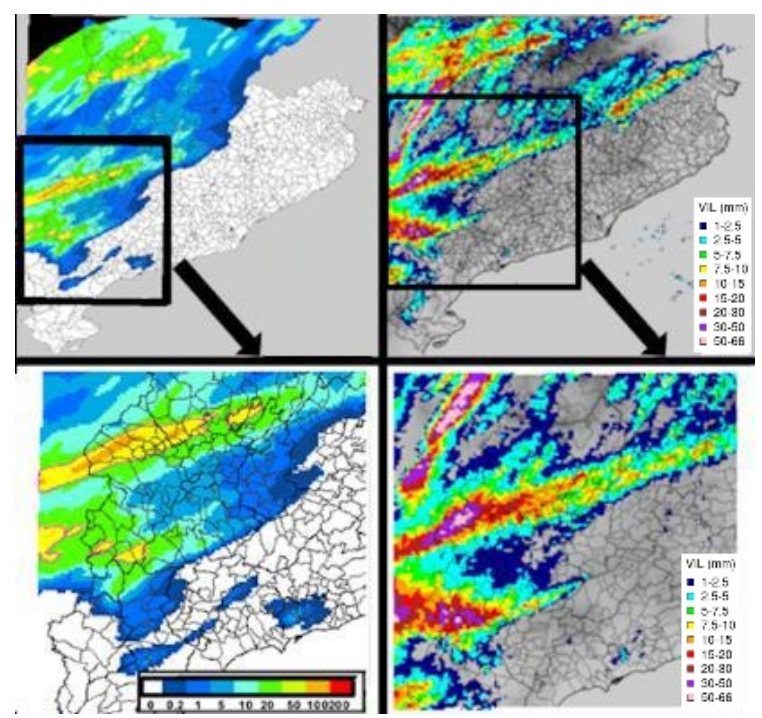

Figure 5: Top: Comparison for one of the first days with the analysis of a hailstorm (5 August 2012). On the left, the map of the quantitative precipitation estimation (QPE) from the XRAD, where the area with QPE exceeding the $50 \mathrm{~mm}$ were labelled as the more probable to be hit by hail (pink line marks the different areas), from the experience of the SMC staff. On the right, the maximum VIL field generated off-line, for comparing with the preliminary product (QPE). Bottom: Zoom to the area marked in the rectangle in the top panel for both products.

and only for the Segrià county (on the Lleida Plain, which corresponds to the western part of Section -SEC- 1 in the bottom map of Fig. 2), the necessity to create a map delimiting the area with a higher probability of hailfall was detected. They also detected the limitation of the $\mathrm{POH}$ product for delimiting the most affected area. Bearing in mind that the DARP staff have some experience with Geographic Information System (GIS) tools, it was agreed to generate geo-referenced maps of VIL, instead of the initial rainfall data. The format of the new product is geotiff and it uses the system of referenced coordinates: "+proj=utm +zone $=31$ +ellps $=$ GRS 80 +units $=\mathrm{m}$ +no_defs", where $u t m$ is the projection type, the zone considered is $31 \mathrm{~N}$, the ellipsoid projection is GRS80, and the units of the maps are meters. This is one of the standard systems used by the Catalan public administration (see the INSPIRE project page $^{1}$ ). In addition, the GIS tool allows different fields to be shown (administrative borders, geographic properties, product matrices, among others) in geo-referenced layers, which means that all of them can be combined by extracting information in specific points and/or areas of interest. Then, if the DARP staff can combine the SMC product with the agricultural exploitation limits field, they can infer those regions more affected by the hailfall.

The maps of the initial events were focused on the exclusive solicited period and consisted of the maximum value of the VIL in each cell ( $1 \times 1 \mathrm{~km}^{2}$ of resolution), using the raster (Hijmans, 2019) and rgdal (Bivand et al., 2018) packages of the $\mathrm{R}$ software ( $\mathrm{R}$ Core Team, 2013). Once

\footnotetext{
${ }^{1}$ http://territori.gencat.cat/ca/detalls/Article/ICC-INSPIRE.Interoperabilitat-de-dades-00002
} 


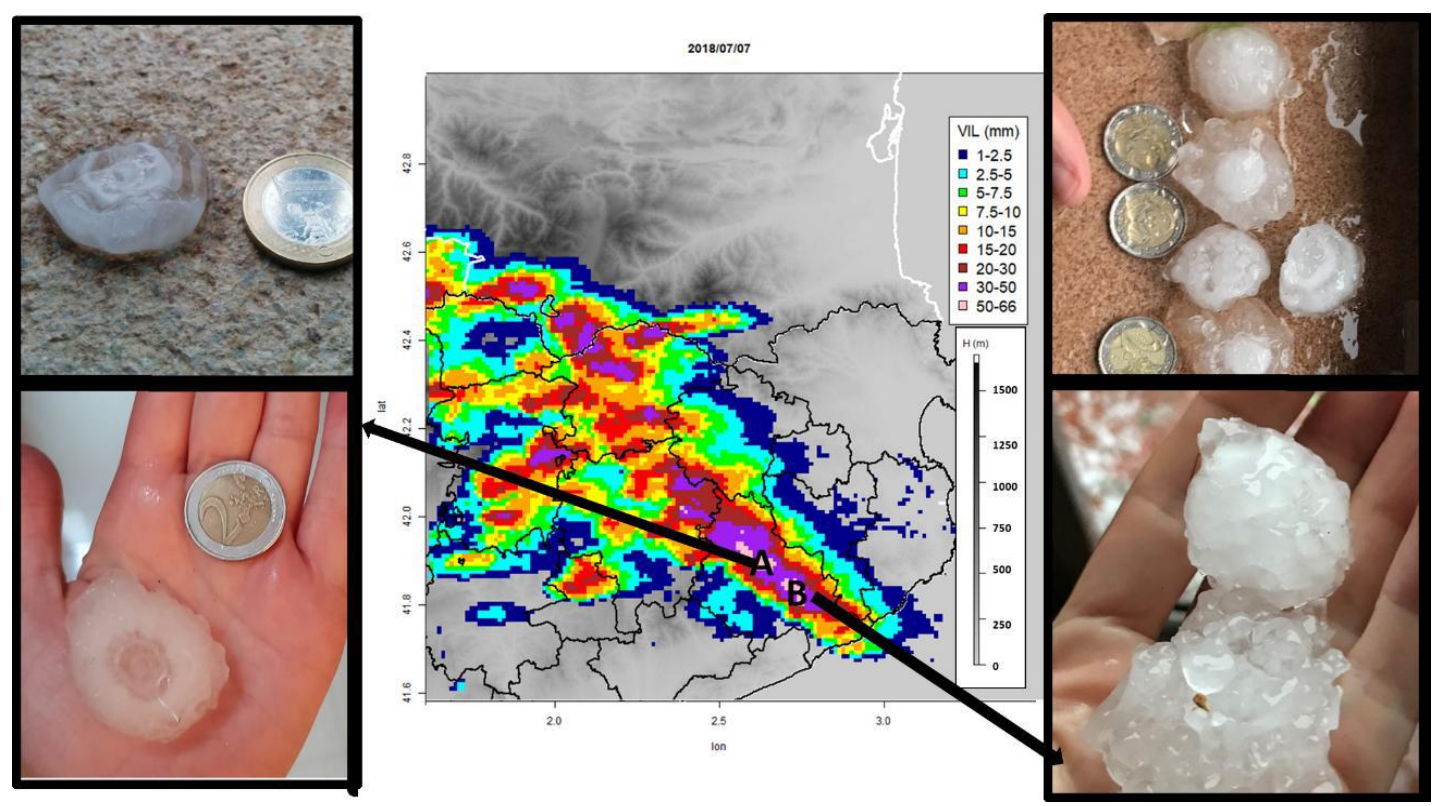

Figure 6: Centre: Map of the maximum VIL estimated by the XRAD for 7 July 2018. Left and right: Some photographs of the hail registered in the most affected locations (indicated in the top panel): Santa Coloma de Farners (A) and Vidreres (B).

the DARP staff had received and analysed the map, they had better knowledge of the hailstorm behaviour. From this information, they were able to optimize their work, focusing their efforts on studying those areas with a higher probability of being affected. Moreover, the analysis is sensitive to the stage of fruit in the fruit trees. The more advanced the fruit is in its maturing phase, the more damage will be caused by the hail. Once the DARP technicians have reported the event, they send this to the SMC. This information helps to improve the hailstorm database, which is necessary when analysing the performance of the different tools used. It is relevant to bear in mind that the lack of information or a wrong value can lead to an underestimation of the skill scores.

Since 2017, the technique has been modified, with slight changes proposed by the two teams: using the maximum daily values of the VIL, the selection of particular areas always with the same extent, or the automation of the script for the generation of the fields. Regarding the second point, sections 1, 2 and 3 (SEC1, SEC2, and SEC3, respectively) are the current ones. SEC1 considers an increase in the initial area previously presented, including practically all the agricultural exploitations on the Lleida Plain. The new range was defined at the beginning of the 2018 campaign. SEC2 was introduced in 2018, and initially covered only the central part. However, the technicians in the Girona area decided to enlarge the region shown in Fig. 2 in order to consider all the fruit tree zones. Finally, SEC3 began to be active in 2019. Table 2 shows how the interaction with the SEC1 staff is more fluent because of the greater experience, the larger number of events and, also, the interest in the region in providing the maps showing how they are affected, because of the economic influence of the agriculture business.

To sum up, the DARP staff can combine the layers of the daily maximum VIL, which estimates the maximum hail size, to the exploitation area field. From this point, the intersection generated with the GIS indicates the most affected areas. However, the technicians must bear in mind the month of the year in order to determine the state of growth of the crop, to improve the quality of the associated degree of damage.

\section{Case studies}

In this section, we introduce some unusual cases that occurred between 2018 and 2019, in order to illustrate different realities found in the operations. We show a single event for sections 2 and 3. However, we present 3 cases for section 1 , because of the higher rate of hailfall with different casuistic.

\subsection{Section 2: 7 July 2018}

The convection that day started at 12.00 UTC in the Central Catalan Pyrenees, moving fast to the south-west. A multi-cell system was developed some hours later, allowing the growth of some significant deep convective thunderstorms inside it. The resulting daily maximum VIL field (Fig. 6) shows a large area with values of over $50 \mathrm{~mm}$ (near $48 \mathrm{~km}^{2}$ ), with the highest value of $65 \mathrm{~mm}$ (the maximum provided by the product).

Although section 2 is commonly hit by severe hailstorms practically yearly, affecting the fruit trees in the region, the contact between the SMC and the DARP in this region had been very limited before this event. This hailstorm, with reported sizes of over $4 \mathrm{~cm}$ in some places (see Fig. 6), seemed to produce significant damage to the agriculture 


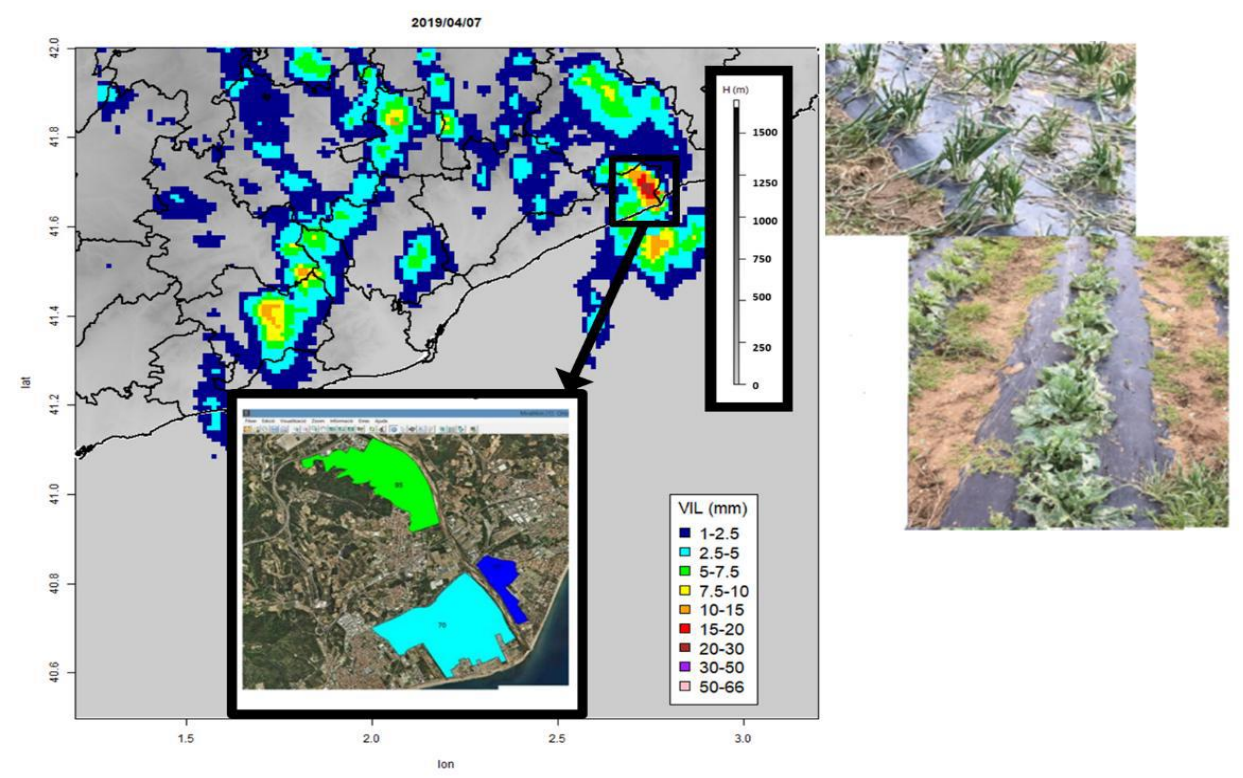

Figure 7: Left: Map of the maximum VIL estimated by the XRAD for 7 April 2019. The zoomed box shows the resulting map of effects in the different agricultural exploitations. Right: some pictures of the damage, all provided by the DARP staff.

Table 2: Number of events with daily maximum VIL fields generated (only considering the current method) for the campaigns 2017, 2018 and early 2019.

\begin{tabular}{cccc}
\hline Section & SEC1 & SEC2 & SEC3 \\
\hline Number of events & 15 & 1 & 1
\end{tabular}

of the area and, besides, it was the starting point of the collaboration between the two organisations. However, the results were not as good as expected, in the sense of the low amount of information returned. This fact could be associated to real low effects on agricultural exploitations.

\subsection{Section 3: 7 April 2019}

This case occurred between 12.00 and 15.00 UTC and was produced also by a multi-cell system, which was poorly organized and with lower reflectance values than the previous one. Only one of their cells presented significant values, probably associated to the interaction of the topography and the outbound flows of other cells. These values were the cause of the maximum daily VIL register $(24 \mathrm{~mm}$, see Fig. 7).

Events in early April are not usually damaging for agriculture. However, the episode in question was an exception. It was also the first collaboration between section 3 DARP staff and the SMC, and it was interesting in the sense of the great rapport between both organisations. Fig. 7 shows the information provided in this case, in which a moderate hailstorm affected the northern area of the central coast of Catalonia. The main characteristic of the case was a contrast between relatively low VIL values (with respect to other examples) and the major reported damages. In this sense, this is an example of how the effects are a combination of the intensity of the thunderstorm and the vulnerability of the terrain.

\subsection{Section 1: 5 September 2018}

In 2018, the hailstorms were not significant in section 1, at least compared to the climatology. However, the collaboration between the SMC and the different DARP teams working in this area increased notably. To this end, both teams analysed almost all the hailfall that occurred. In this piece of work, we present the three most remarkable ones. The first one took place in the last part of the campaign (which ran from late April to mid-September). In most of the cases, VIL maps showed moderate to high values, but the area affected was not especially vulnerable (Fig. 8). No registers of damage or negative effects were found for this case for two reasons. Firstly, the hail occurred after another one shown in the next subchapter. In addition, the collection of fruit in the area had taken place before early September. In any case, the event serves as an example to compare with the two other ones.

The episode, like many others affecting the section, was marked by some thunderstorms coming from the west. At 00.00 UTC, a linear convective structure with many cells was a few kilometres west of the Catalan border. However, a few minutes later, the squall line broke its shape and only a single thunderstorm penetrated section 1. The VIL field presented a quasi-linear form associated with the path of the hailstorm, and the values reached $42 \mathrm{~mm}$.

\subsection{Section 1: 4 September 2018}

During the morning, some small thunderstorms affected the Section 1 area. However, it was during the afternoon 


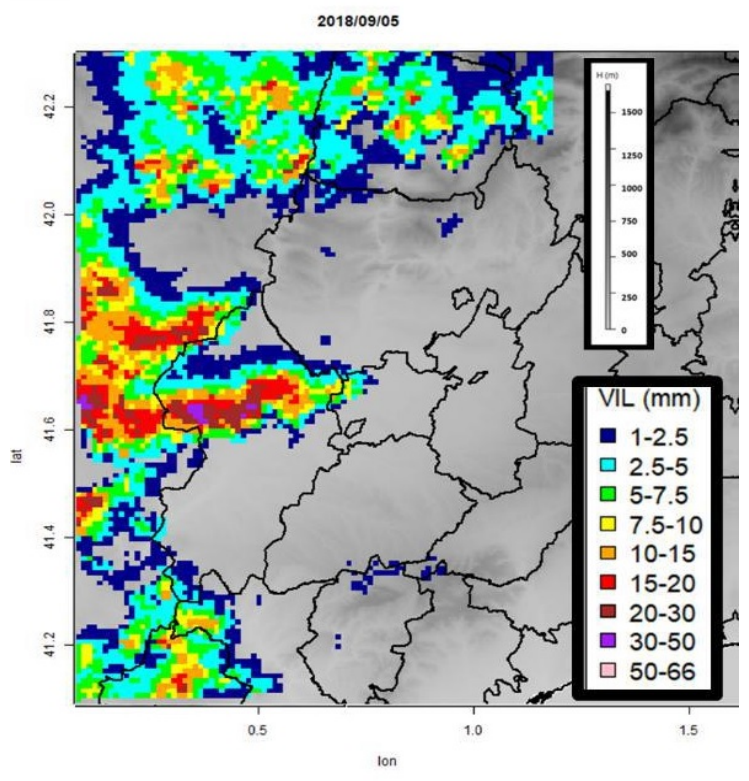

Figure 8: Map of the maximum VIL estimated by the XRAD for 5 September 2018.

(12.30-15.30 UTC) when a deep isolated cell rose in the SW of the Section, moving E-NE, with an unusual trajectory. The maximum daily VIL was $63.8 \mathrm{~mm}$, while the area over 50 mm was of $17 \mathrm{~km}^{2}$.

The event was the most relevant one in section 1 for the analysis period. The case occurred the day before the previous one presented. The main feature was the localization of the hailstones in a very reduced area (see Fig. 9). The importance of the VIL field, in the bottom panel of the figure, shows a good correlation between the regions with high values and the reported effects on the ground.

\subsection{Section 1: 20 July 2018}

This last case (Fig. 10) reproduced a similar situation to the first one presented for the same section (Fig. 8). The information provided by the SMC was very important to the DARP staff at the time to delimit the different levels affected , which are very coincident, again, with the daily max VIL (in this case, the value was higher, close to $55 \mathrm{~mm}$, with $5 \mathrm{~km}^{2}$ over $50 \mathrm{~mm}$. The evolution of both episodes was practically the same, with only the direction of propagation of the thunderstorms changing (W-NW instead of W).

We have analysed the correlation between the maximum municipal VIL and the degree of damage shown in the previous figure. It is important to bear in mind that the main problem consists of the fact that the damage only concerns agricultural exploitations, while the maximum hailfall estimation can occur in other areas. For this reason, the results must be carefully considered. In any case, we found that the most affected municipalities (Alcarràs and Gimenells i Pla de la Font, marked with a red dot) presented large values of daily maximum VIL (51.8 and $39 \mathrm{~mm}$, respectively) of the median (21 and $16 \mathrm{~mm})$ and, what is

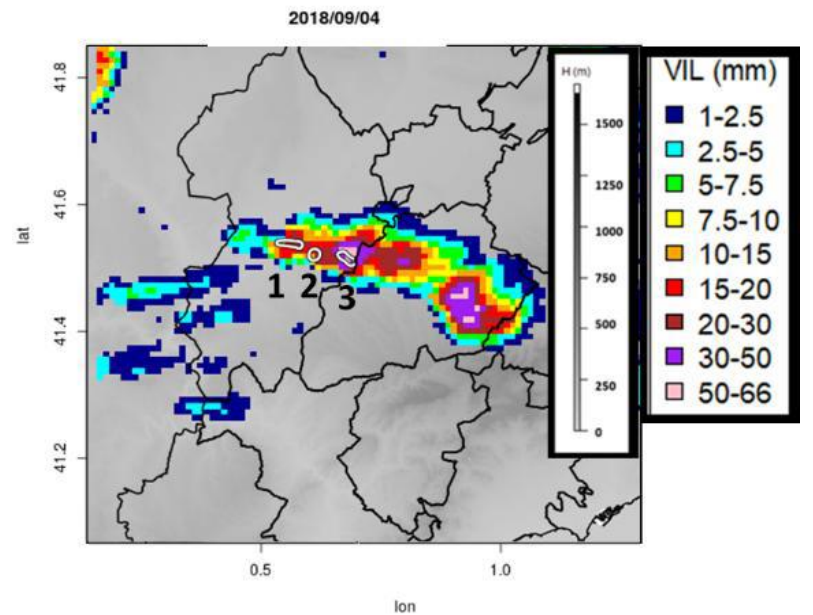

Figure 9: Top: Map of the maximum VIL estimated by the XRAD for 4 September 2018. Bottom: Affected areas delimited by the DARP staff (purple shaded regions) compared with the daily VIL field. Labels 1, 2 and 3 show the affected crop areas, according to the DARP staff report.

more important, extensive areas with values greater than $10 \mathrm{~mm}$ (100\% and $85 \%$, respectively). The municipalities marked with an orange dot (Almacelles, Torrefarrera and the northern part of Lleida) presented significant values of the preceding parameters. However, in all the localities some of them showed less significant amounts (in particular, the median and the area covered by high VIL rates). Therefore, we consider that we need to analyse a broader set of cases before giving numerical results.

\section{Discussion and future work}

The methodology has helped to perform the fieldwork application to hailstorm events more easily. Besides, it has extended to most of the regions where hail events affect agricultural exploitations in Catalonia, optimizing the resources of the Administration. The first objective of the project, to make the agreement robust, was achieved during the 2018 and early 2019 campaigns. However, some aspects must change in the future.

The first matter that needs improving is the automation of the procedure. Thus, each time that the VIL product reaches a determined threshold, the processes of generation, adaptation and sending of the product will occur. Taking into account that the SMC has advanced at this point in other projects, it looks relatively easy to achieve this goal in the near future.

Finally, we need to consider the selection of different thresholds depending on the region and the season of the year. As previously shown, and from the results of the last campaigns, different values of the VIL can produce similar effects depending on the season of the year. Moreover, the damage to the exploitation depends also on the crop type, in conjunction with growth stage. Comparable conditions in different months in the VIL fields can lead to an ample 


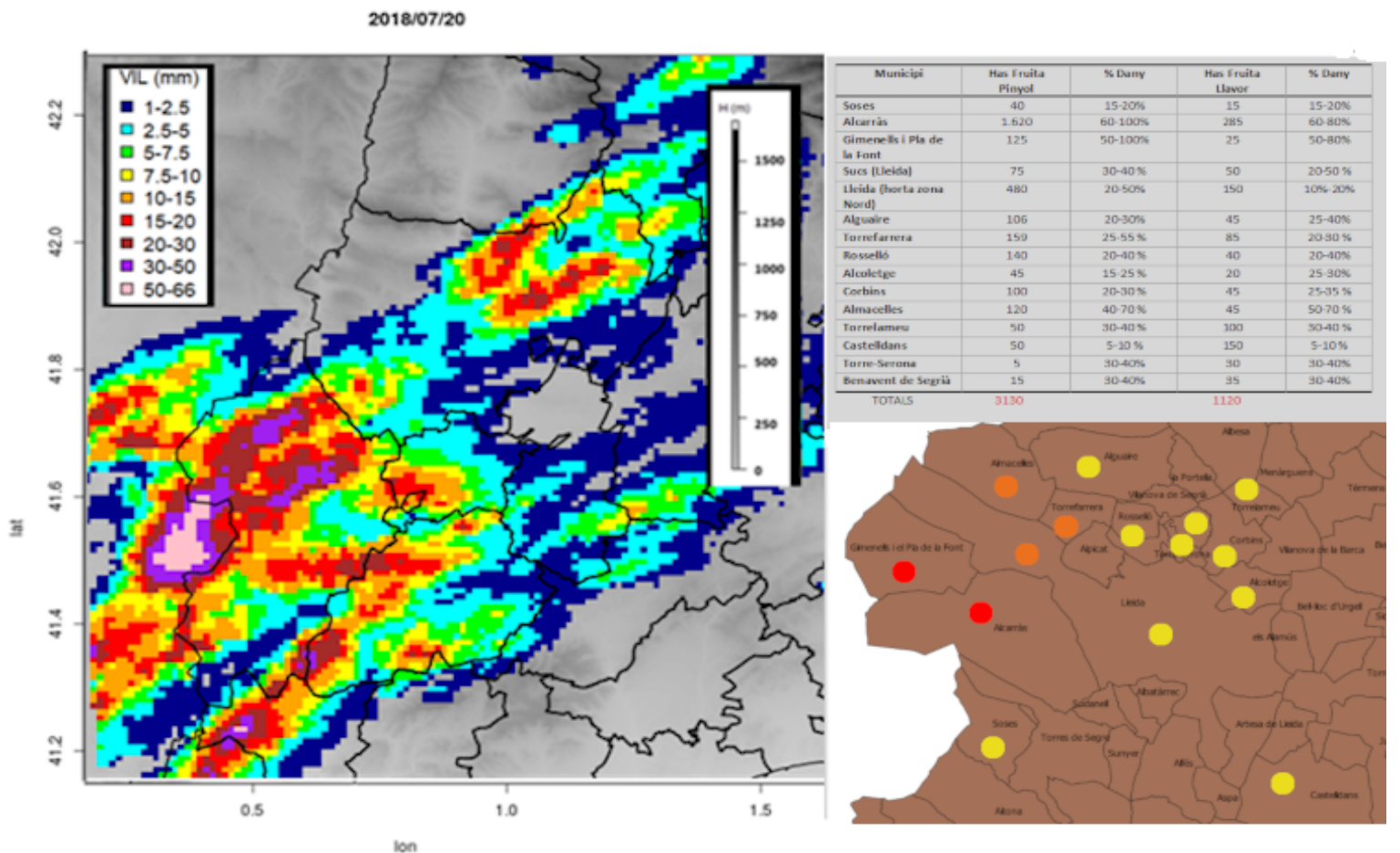

Figure 10: Top: Map of the maximum VIL estimated by the XRAD for 2 July 2018. Bottom: Table of average damage to crops separated by municipalities (each row) and type (stone or seed, in columns), and the map (zoom of the rectangle of the top panel) focused on the municipalities. The colour of the dot indicates the affected extent: red (high), orange (mid) and yellow (low).

spectrum of losses (from none to catastrophic). Because of this, we need to perform some climatic analyses to tune the thresholds. These thresholds can also be used in the future for better discriminating the areas more prone to be analysed, always integrating them into a GIS that can include other layers, such as the use of the terrain.

\section{Conclusions}

We have presented the first stage of a collaboration project between the Meteorological Service of Catalonia and the Department of Agriculture, Livestock and Fishing of the Generalitat de Catalunya, which consists of the generation of maximum VIL maps. These fields are highly effective for doing field work on hailstorm events. The project was born as a simple collaboration between the SMC and a public administration office and has grown to include the three main areas of agricultural exploitation in the region. From the analysis of the SMC's hail database, we have observed that the effect of hail in Catalonia is marked by large time and spatial variability. Moreover, the probability of occurrence of hail is high in practically all the territory, with two marked maxima: the western region and the central part.

The first results indicate that the DARP staff have found a tool that helps them to analyse the events over the terrain. In addition, they return very helpful information to the SMC about the characteristics of the events on the ground. This data collected is included in the SMC's database of severe weather, helping to improve knowledge about this type of thunderstorm, and how we can better diagnose and forecast them in the future. We have also observed how the intensity of the event is not the only element involved in the effect on human activities. To this end, the DARP staff can combine different layers, such as the daily maximum VIL (correlated with the maximum hail size), or the exploitation area field, with the intersection being the most probably affected areas.

We plan to continue the collaboration in order to include future improvements of the procedure, which could optimize the tool for the analysis in near real-time of hail events that affect areas that are highly dependent on agriculture. Finally, we think that the adaptation of this simple technique could help many other regions with similar effects of hail on agriculture. The adaptation of this technique to other regions depends mainly on the existence of a radar or a radar network, and a team with tasks focused on the analysis of the effect of hail on crops. Both are important to the same degree, because without the remote sensing it is very difficult to delimit the effect and, in addition, the human eye is essential for confirming the previous estimation, helped by other tools such as GIS and some layers such as the exploitation limits or the type of crops, among others.

Acknowledgements. The authors would like to thank all the staff at the DARP who collaborated in the development of the current product, who helped to improve the methodology and who used the fields for making the analysis of the field work easier. We would also like to thank the two anonymous reviewers for helping to improve our manuscript. 


\section{References}

Allen, J.: Hail Size: What We Know Around the World, proceedings of the 2nd European Hail Conference KIT, Kahrlsruhe Institute of Technology, and University of Bern, 2017.

Amburn, S. A. and Wolf, P. L., 1997: VIL density as a hail indicator, Weather Forecast., 12, 473-478.

Aran, M., Sairouni, A., Bech, J., Toda, J., Rigo, T., Cunillera, J., and Moré, J., 2007: Pilot project for intensive surveillance of hail events in Terres de Ponent (Lleida), Atmos. Res., 83, 315335.

Aran, M., Pena, J., and Torà, M., 2011: Atmospheric circulation patterns associated with hail events in Lleida (Catalonia), Atmos. Res., 100, 428-438.

Bivand, R., Keitt, T., and Rowlingson, B.: rgdal: Bindings for the 'Geospatial' Data Abstraction Library, r package version 1.3-6. https://CRAN.Rproject.org/package=rgdal, 2018.

Boudevillain, B. and Andrieu, H., 2003: Assessment of vertically integrated liquid (VIL) water content radar measurement, J. Atmos. Ocean. Technol., 20, 807-819.

Ceperuelo, M., Llasat, M., and Rigo, T.: Rainfall events and Hailstorms Analysis Program (RHAP), ADGEO, 7.

del Moral, A., del Carmen Llasat, M., and Rigo, T., 2017: Identification of anomalous motion of thunderstorms using daily rainfall fields, Atmos. Res., 185, 92-100.

del Moral, A., Rigo, T., and Llasat, M. C., 2018: A radar-based centroid tracking algorithm for severe weather surveillance: identifying split/merge processes in convective systems, Atmos. Res., 213, 110-120.

Delobbe, L. and Holleman, I., 2006: Uncertainties in radar echo top heights used for hail detection, Meteorol. Appl., 13, 361374.

Edwards, R. and Thompson, R. L., 1998: Nationwide comparisons of hail size with WSR-88D vertically integrated liquid water and derived thermodynamic sounding data, Weather Forecast., 13, 277-285.

Farnell, C. and Llasat, M. d. C., 2013: Proposal of three thermodynamic variables to discriminate between storms associated with hail and storms with intense rainfall in Catalonia (Proposta de tres variables termodinàmiques per discriminar entre tempestes amb pedregades i tempestes amb pluges intenses), Tethys, 10, $25-34$.

Farnell, C., Rigo, T., and Pineda, N., 2017: Lightning jump as a nowcast predictor: application to severe weather events in Catalonia, Atmos. Res., 183, 130-141.

Farnell, C., Rigo, T., and Martin-Vide, J., 2018a: Application of cokriging techniques for the estimation of hail size, Theor. Appl. Climatol., 131, 133-151.

Farnell, C., Rigo, T., and Pineda, N., 2018b: Exploring radar and lightning variables associated with the Lightning Jump. Can we predict the size of the hail?, Atmos. Res., 202, 175-186.

García-Ortega, E., Merino, A., López, L., and Sánchez, J., 2012: Role of mesoscale factors at the onset of deep convection on hailstorm days and their relation to the synoptic patterns, Atmos. Res., 114, 91-106.

Hijmans, R. J.: raster: Geographic Data Analysis and Modeling, $\mathrm{r}$ package version 2.8-19. https://CRAN.Rproject.org/package=raster, 2019.

Hirano, K. and Maki, M., 2010: Method of VIL calculation for Xband polarimetric radar and potential of VIL for nowcasting of localized severe rainfall-Case study of the Zoshigaya downpour, 5 August 2008, Sola, 6, 89-92.

Ortega, K. L., Krause, J. M., and Ryzhkov, A. V., 2016: Polarimetric radar characteristics of melting hail. Part III: Validation of the algorithm for hail size discrimination, J. Appl. Meteorol. Climatol., 55, 829-848.

Palencia, C., Berthet, C., Massot, M., Castro, A., Dessens, J., and Fraile, R., 2007: On the individual calibration of hailpads, Atmos. Res., 83, 493-504.

Porras, I., Sairouni, A., and Aran, M.: Climatologia de la probabilitat de calamarsa a Catalunya, Tech. Rep. 74, notes d'Estudi del Servei Meteorològic de Catalunya.

Punge, H., Bedka, K., Kunz, M., and Werner, A., 2014: A new physically based stochastic event catalog for hail in Europe, Nat. Hazards, 73, 1625-1645.

Punge, H. J., Bedka, K., and Kunz, M.: Hail frequency in Europe, proceedings of the 2nd European Hail Conference KIT, Kahrlsruhe Institute of Technology, and University of Bern, 2017.

Ramis, C., Arús, J., López, J. M., and Mestres, A. M., 1997: Two cases of severe weather in Catalonia (Spain): an observational study, Meteorol. Appl., 4, 207-217.

R Core Team, 2013: R: A language and environment for statistical computing, https://www.R-project.org/.

Rigo, T. and Llasat, M. C., 2016: Forecasting hailfall using parameters for convective cells identified by radar, Atmos. Res., 169, 366-376.

Saltikoff, E., Tuovinen, J.-P., Kotro, J., Kuitunen, T., and Hohti, H., 2010: A climatological comparison of radar and ground observations of hail in Finland, J. Appl. Meteorol. Climatol., 49, 101-114.

Schultz, C. J., Petersen, W. A., and Carey, L. D., 2011: Lightning and severe weather: A comparison between total and cloud-toground lightning trends, Weather Forecast., 26, 744-755.

Schuster, S. S., Blong, R. J., and Speer, M. S., 2005: A hail climatology of the greater Sydney area and New South Wales, Australia, Int. J. Climatol., 25, 1633-1650.

Waldvogel, A., Federer, B., and Grimm, P., 1979: Criteria for the detection of hail cells, J. Appl. Meteorol., 18, 1521-1525. 